\title{
CRESCIMENTO E ANATOMIA FOLIAR DE PLANTAS JOVENS DE Mikania glomerata Sprengel (GUACO) SUBMETIDAS A DIFERENTES FOTOPERÍODOS
}

\author{
EVARISTO MAURO DE CASTRO \\ JOSÉ EDUARDO BRASIL PEREIRA PINTO ${ }^{2}$ \\ AMAURY ALVES ALVARENGA ${ }^{2}$ \\ ÉRICO DE CASTRO LIMA JÚNIOR ${ }^{5}$ \\ SUZAN KELLY VILELA BERTOLUCCI ${ }^{4}$ \\ JOÃO LUIS DA SILVA FILHO ${ }^{5}$ \\ CARLOS VINICIO VIEIRA ${ }^{3}$
}

\begin{abstract}
RESUMO - Mikania glomerata Sprengel é uma importante espécie medicinal popularmente conhecida como guaco, coração-de-jesus, guaco-liso, guacocheiroso, cipó-caatinga e erva-de-cobra. Foram estudados os fotoperíodos de 8, 12, 16 e 20 horas. Após 90 dias de tratamento, determinaram-se o peso de matéria seca total, particionada (entre folhas, ramos e raízes), área foliar, razão de área foliar, razão de peso foliar e área foliar específica. $\mathrm{O}$ crescimento das plantas variou em função do fotoperíodo, havendo um acréscimo na matéria seca total e particionada até 16 horas de fotoperíodo, seguido de uma queda, quando o fotoperíodo foi aumentado de 16 para 20 horas. A área foliar e o
\end{abstract}

número de folhas foram crescendo até o fotoperíodo de 20 horas. Houve redução da área foliar específica e na razão de área foliar com o aumento do fotoperíodo. Quanto à razão de peso foliar, houve também um decréscimo nesse caráter quando o fotoperíodo aumentou de 8 para 16 horas; em contrapartida, quando o fotoperíodo aumentou de 16 para 20 horas, houve uma tendência de aumento. Foi verificado efeito dos tratamentos no espessamento dos tecidos foliares. O fotoperíodo influenciou positivamente as características associadas ao crescimento, anatomia foliar e fotossintética, como produção de biomassa total, área foliar, número de folhas, particionamento de biomassa para os diversos órgãos da planta.

TERMOS PARA INDEXAÇÃO: Mikania glomerata, anatomia, fotoperíodo, planta medicinal.

\section{GROWTH AND FOLIAR ANATOMY OF Mikania glomerata Sprengel ("GUACO") PLANTS SUBMITTED TO DIFFERENT PHOTOPERIOD}

\begin{abstract}
Mikania glomerata Sprengel, an important medicinal species, popularly known as "guaco", "coração de Jesus", "guaco liso", "guaco cheiroso", "cipó caatinga" and "erva de cobra" was investigated. The photoperiods of $8,12,16$ and 20 hours were studied. After 90 days' treatment; total dry matter weight, partitioned (among leaves, branches and roots), leaf area, leaf area ratio, leaf weight ratio and specific leaf area were determined. The plants growth changed with photoperiod there was an increase in the total and partitioned dry matter up to 16 hours followed by a fall when photoperiod was increased from 16 to 20
\end{abstract}

INDEX TERMS: Mikania glomerata, anatomy, photoperiod, medicinal plant.

1. Engenheiro Florestal, Dr., UNIVERSIDADE FEDERAL DE LAVRAS/UFLA, Caixa Postal 37, 37200-000, Lavras, MG.

2. Engenheiro Agrônomo, Dr., UFLA.

3. Estudante de iniciação cientifica, DBI/UFLA.

4. Farmacêutica, Msc., UFLA.

5. Engenheiro Agrônomo, Mestrando, UFLA. 


\section{INTRODUÇÃO}

Mikania glomerata Sprengel é uma espécie medicinal popularmente conhecida como guaco, "coração-dejesus", guaco-liso, guaco-cheiroso, cipó-caatinga e erva-decobra, pertencente à família Asteraceae, tribo Eupatorieae e subtribo Mikaninae. O gênero Mikania é composto de aproximadamente 450 espécies distribuídas em regiões tropicais da América, África e Ásia. Dessas, cerca de 150 são encontradas no Brasil (PEREIRA, 1997).

Em muitas espécies de uso medicinal tem sido evidenciada em alguns estudos a plasticidade fisiológica e anatômica, em função das condições ambientais de cultivo (LETCHAND e GOSSELIN, 1996). A luz, um dos principais fatores do ambiente físico, age de forma isolada ou conjuntamente no controle do desenvolvimento das plantas, interferindo no crescimento por meio do processo fotossintético e na diferenciação durante a morfogênese. Sua ação pode ser vista em termos quantitativo (intensidade luminosa ou densidade de fluxo de fótons), qualitativo (espectro da radiação eletromagnética azul e vermelha) e duração (fotoperíodo).

Diante da significativa carência de informações a cerca do comportamento dessa espécie no que se refere a fatores do ambiente físico, em particular ao fotoperíodo, procurou-se neste trabalho estudar aspectos relativos às características de crescimento e anatomia foliar de guaco (Mikania glomerata Sprengel) sob diferentes condições fotoperiódicas.

\section{MATERIAL E MÉTODOS}

Este estudo foi conduzido em sala de crescimento do Laboratório de Ecofisiologia de Propagação de Plantas do Departamento de Biologia da Universidade Federal de Lavras (MG), no período de março a agosto de 2001. A instalação do experimento ocorreu com a formação das mudas de guaco a partir de estacas de 15 $\mathrm{cm}$ de comprimento retiradas do terço médio dos ramos. As estacas contendo dois pares de folhas foram colocadas em bandejas de poliestireno expandido (isopor). O substrato utilizado foi o PLANTMAX. A propagação das mudas ocorreu em casa-de-vegetação com umidade relativa de $75 \%$ e temperatura de $26 \pm 2{ }^{\circ} \mathrm{C}$, durante 60 dias. Após esse período, foram colocadas em saco plástico perfurados de $25 \times 20 \mathrm{~cm}$, com capacidade para $4 \mathrm{Kg}$. O substrato foi constituído por uma mistura de vermiculita, esterco bovino curtido e terra de subsolo, na proporção 20:30:50.

Plantas com 60 dias de idade foram transferidas para câmaras de crescimento no Setor de Fisiologia Ve- getal/ UFLA e submetidas aos seguintes tratamentos fotoperiódicos: 8, 12, 16, e 20 horas. Em cada tratamento fotoperiódico foram utilizadas 8 plantas. Essas câmaras são móveis e dotadas de uma mesa ajustável com iluminação artificial fornecida por $75 \%$ de lâmpadas fluorescentes (marca G-E, 40W) e $25 \%$ de lâmpadas do tipo Gro-Lux (Marca Sylvânia), emitindo uma radiação ao redor de $225 \mu \mathrm{mol}$ de quanta $/ \mathrm{m}^{2} / \mathrm{seg}$. A radiação foi determinada por meio de um porômetro (STEADY STATE Porometer LICOR 1600 M). Em cada câmara foi adaptada uma cortina de tecido tipo "Black Out", sendo cada carrinho dotado de um sistema temporizador, com acionamento e desligamento automáticos. Essas condições permitiram que se trabalhasse independentemente com os quatro fotoperíodos numa mesma sala de crescimento. A temperatura ambiente foi controlada por meio de um aparelho de ar condicionado, registrando uma temperatura media de $25^{\circ} \mathrm{C} \pm 3^{\circ} \mathrm{C}$ e umidade relativa do ar de $15 \%$, monitorada por um psicrômetro.

Em razão do hábito volúvel dessa espécie, as plantas foram tutoradas, por meio de estacas de bambu, permanecendo em condições de câmara por um período de 90 dias. Durante esse período de condução, foi realizada irrigação dos recipientes, fazendo com que o substrato mantivesse sua umidade próxima à capacidade de campo.

$\mathrm{O}$ delineamento experimental utilizado foi o inteiramente casualizado, sendo os tratamentos representados por quatro fotoperíodos $(8,12,16$ e 20 horas), com 8 repetições e uma planta por repetição, num total de 32 parcelas. Após 90 dias do início do experimento, foram analisadas as seguintes características relacionadas ao crescimento: biomassa seca total e particionada (folhas, ramos e raízes), área foliar (A), área foliar específica (AFE), razão de área foliar (RAF), razão de peso foliar (RPF) e número de folhas. A área foliar total da planta foi medida pelo Medidor de Área Foliar-LICOR, Mod. LI-3100.

Após a separação da planta em folhas, ramos e raízes, as partes foram acondicionadas em sacos de papel, identificadas e colocadas para secar em estufa. As raízes foram lavadas em água corrente para retirar o substrato aderido e colocadas em estufa com circulação forçada de ar, com temperatura de $70^{\circ} \mathrm{C}$ até peso constante. As folhas e ramos foram colocados em estufa a $40^{\circ} \mathrm{C}$ até atingirem peso constante. A pesagem foi feita em balança analítica digital com precisão de quatro dígitos.

A razão de área foliar (RAF), razão de peso foliar (RPF) e área foliar especifica (AFE) foram determinadas a partir dos valores de área foliar (A) expressos em $\mathrm{dm}^{2}$, peso de matéria seca da planta $(\mathrm{P})$ e peso de matéria seca das folhas $(\mathrm{Pt})$, ambos expressos em $\mathrm{g}$, empre-

Ciênc. agrotec., Lavras. V.27, n.6, p.1293-1300, nov./dez., 2003 
gando-se as seguintes equações, de acordo com Benincasa (1988): $\mathrm{RAF}=\mathrm{A} / \mathrm{P} \quad \mathrm{RPF}=\mathrm{Pt} / \mathrm{P} \quad \mathrm{AFE}=\mathrm{A} / \mathrm{Pt}$.

As determinações da espessura foliar foram efetuadas mediante seções transversais de 10 folhas obtidas de 5 plantas em três regiões da planta (superior, mediana e basal do ramo), após montagem em lâminas semipermanentes. Com o auxílio de ocular micrométrica, foram realizadas 20 medições da espessura das epidermes adaxial e abaxial e dos parênquimas paliçádico e esponjoso, nas três regiões da planta. Portanto, a amostra foi constituída de 60 medições para cada fotoperíodo.

\section{RESULTADOS E DISCUSSÃO}

Verifica-se pelos dados obtidos que o padrão de desenvolvimento das plantas variou em função do fotoperíodo, tanto no acúmulo de matéria seca total, quanto particionada entre folhas, caules e raízes. Para matéria seca total, os desvios da regressão quadrática foram significativos ao nível de $5 \%$ de probabilidade. Por esse critério, a equação de regressão quadrática não seria a mais apropriada para explicar o comportamento dos dados. Porém, o coeficiente de determinação, $\mathrm{R}^{2}$, foi superior a $97 \%$, indicando que o modelo adotado expli- ca aproximadamente $98 \%$ da variação total (Figura 1, A). Da mesma forma que a matéria seca total, na matéria seca das raízes, o efeito dos desvios da equação de regressão quadrática foram significativos. Porém, o coeficiente de determinação, $\mathrm{R}^{2}$, foi superior a $89 \%$, indicando que o modelo adequado explica aproximadamente $90 \%$ da variação total (Figura 1, B). O coeficiente de regressão linear para biomassa seca do caule e da folha foi significativo. A estimativa desse parâmetro para caule foi de 0,489 e de 0,776 para folha. Esses valores indicam que para uma variação de uma hora no fotoperíodo, tem-se respectivamente um incremento médio de $0,489 \mathrm{~g}$ e $0,776 \mathrm{~g}$ de biomassa seca para caule e folha (Figura 1, C e D).

Comparando-se a variação de biomassa seca entre os fotoperíodos estudados, verifica-se que os maiores acúmulos de biomassa de raízes ocorreram no fotoperíodo de 16 horas, ao passo que a biomassa de folha e ramo foram maiores quando as plantas foram cultivadas sob 20 horas de fotoperíodo. Esses resultados são coincidentes com os obtidos em outras espécies medicinais, como Symphytum officinale L. (CASTRO, 1999) e Gomphrena macrocephala St.-Hill (MOREIRA et al., 1999).
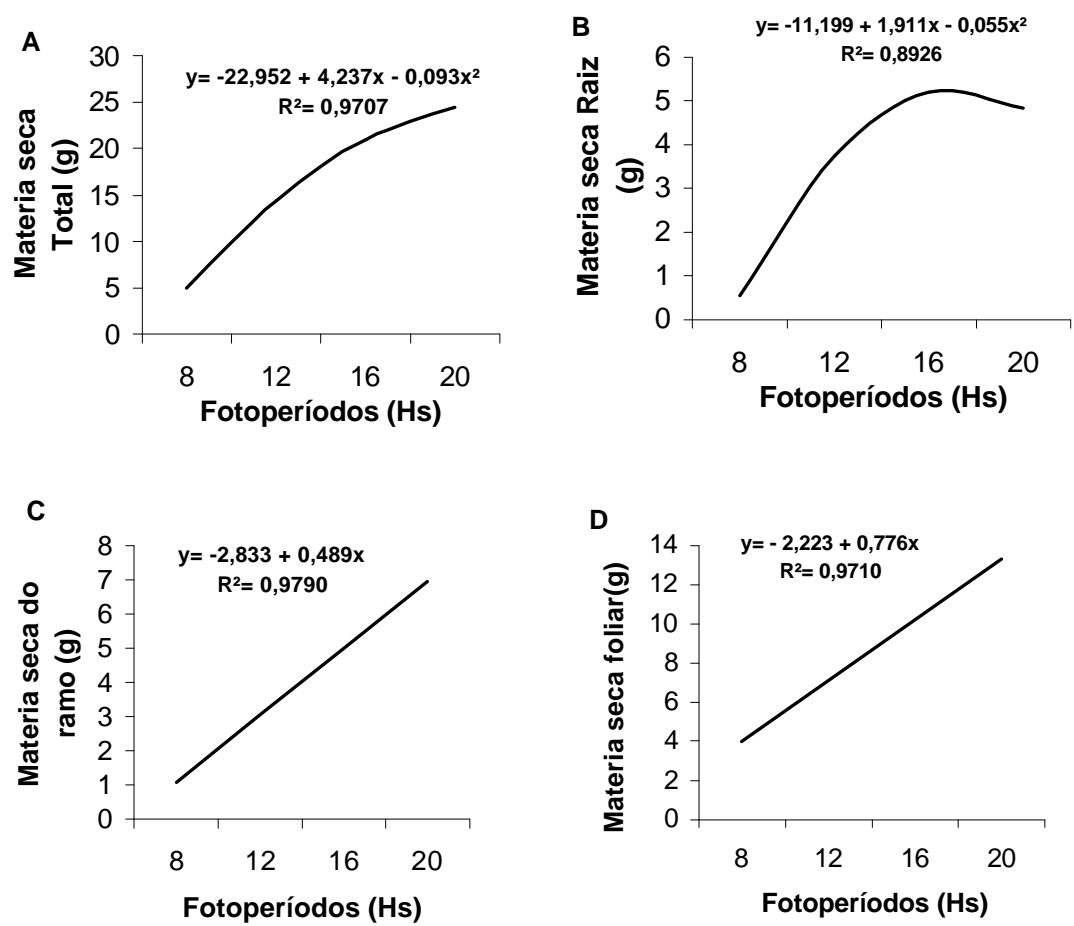

FIGURA 1 - Matéria seca total (A), materia seca das raízes (B), do ramo (C) e das folhas (D) de plantas de Mikania glomerata Spreng. submetidas a diferentes fotoperíodos, após 90 dias.

Ciênc. agrotec., Lavras. V.27, n.6, p.1293-1300, nov./dez., 2003 
A duração do período luminoso desempenha um papel importante no crescimento das plantas, possibilitando a elas maior atividade fotossintética e, conseqüentemente, maior disponibilização e alocação de compostos para o crescimento dos seus diversos órgãos. Aumento na produção de biomassa seca é freqüentemente encontrado em plantas crescidas sob dias longos, mesmo que o tratamento de luz suplementar forneça pouca energia fotossintéticamente ativa. Isso deve ocorrer em função do aumento na área foliar e da produção fotossintética (THOMAS e VINCE-PRUE, 1997). Resultados desse gênero foram evidenciados no presente estudo e alguma semelhança, confirmada em outras espécies (HAY, 1990; RANCANCIO et al., 1996). Contudo, para outras espécies como Oryzopisis miliacea (L.) Benth e Hook ex Asch. e Schweinf (KIGELL e KOLLER, 1970) e Solanum tuberosum L. (ENGELS et al., 1995), foi observado que o acúmulo de biomassa se- ca não foi afetado pelo fotoperíodo, o que evidencia que esse tipo de resposta das plantas em relação à duração de luz não segue o mesmo padrão de crescimento e/ou desenvolvimento. Observa-se (Figura 2) que a distribuição de biomassa seca para os diferentes órgãos das plantas de guaco também variou com os diferentes fotoperíodos. A porcentagem de biomassa direcionada para as raízes aumentou até o limite de 16 horas de luz; a partir daí, observou-se uma queda. $\mathrm{O}$ direcionamento para o caule foi maior em 20 horas, enquanto as folhas concentraram mais biomassa no fotoperíodo de 8 horas. Com esse valor, infere-se que como a duração do período luminoso é menor, a planta necessitando fotossintetizar investiu mais em matéria seca para produção de folha, em comparação aos demais fotoperíodos. Entretanto, pelos resultados, demonstra-se que as plantas de guaco sob todos os fotoperíodos estudados alocam a maior parte de sua produção de biomassa para as folhas.

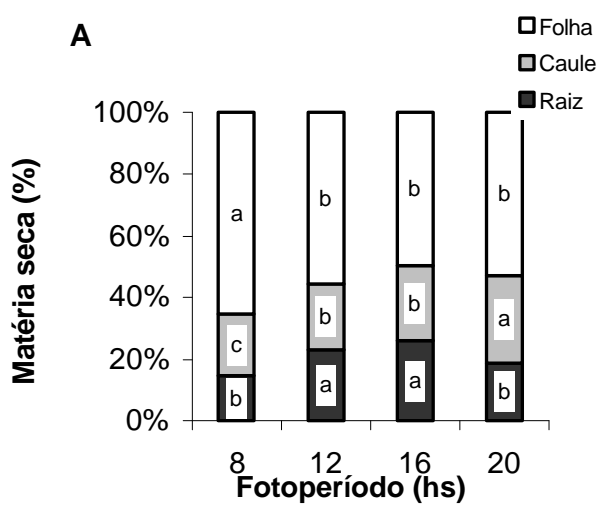

FIGURA 2 - Porcentagem de matéria seca alocada pela planta de guaco para a formação e crescimento de folha, ramo e raiz, em função de diferentes fotoperíodos. As médias seguidas pelas mesmas letras não diferem entre si pelo teste de Scott Knott a 5\% de probabilidade.

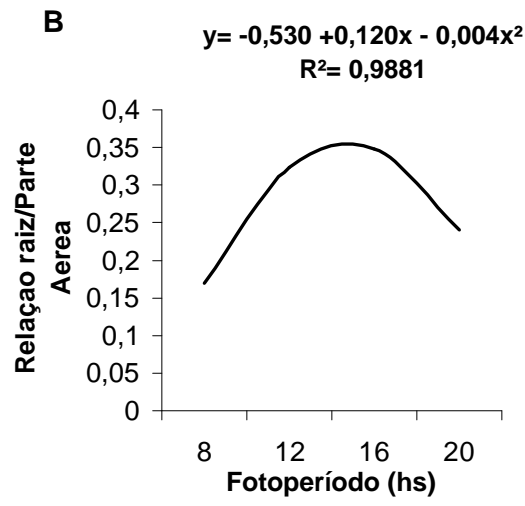

FIGURA 3 - Matéria seca da relação raiz/parte aérea em função de diferentes fotoperíodos. 
Quanto à relação raiz/parte aérea, com base na matéria seca, verifica-se que o coeficiente de regressão quadrática foi significativo ao nível de $1 \%$ de probabilidade. $\mathrm{O}$ ajuste do modelo aos dados pode ser constatado tanto pela insignificância dos desvios de regressão como pelo alto $\mathrm{R}^{2}$ obtido (98,81\%). Observa-se (Figura 3) que houve um acréscimo na relação raiz/parte aérea até 16 horas de fotoperíodo; a partir daí, houve queda nessa relação.

Com relação à área foliar e número de folhas, verifica-se um notável efeito da duração do período luminoso (Figura 4, A e B). O modelo linear foi o que mais se ajustou à característica área/superfície foliar. A estimativa desse parâmetro foi de 1,662 $\mathrm{dm}^{2}$ de área foliar (Figura 4, A). A área foliar é considerada uma característica referencial associada ao processo de capacitação de energia responsável pela produção de matéria orgânica e, conseqüentemente, pelo crescimento basal da planta.

Pelos resultados presentes, confirma-se essa idéia e os mesmos encontram suporte em resultados semelhantes obtidos com outras espécies, como trevo-branco (JUNTILLA et al., 1990), confrei (CASTRO, 1999) e feijão Jacatupé (ALVARENGA, 1987), cujos autores mostram relações diretas entre o aumento no comprimento do dia e aumento da área foliar. Em confrei, Castro (1999) mostrou uma resposta linear até o fotoperíodo de 16 horas. A extensão do fotoperíodo de 8 para 12 horas e de 12 para 16 horas proporcionou, respectivamente, aumentos na área foliar de cerca de $21,15 \%$ e $12,26 \%$, havendo uma queda de $23,24 \%$ em fotoperíodo superior a 16 horas. Independente da classe fotoperiódica da planta, a área foliar em geral tende a ser maior sob dias mais longos em relação a dias curtos (ALVARENGA, 1987).

À semelhança do verificado com a área foliar, o aumento linear do fotoperíodo de 8 para 20 horas pro- moveu um incremento no numero de folhas das plantas de guaco (Figura 4, B). Segundo Benincasa (1988), a área foliar total de uma planta é resultado da ação conjunta de dois componentes, representados pelo tamanho e pelo número de folhas.

Outros índices fisiológicos do crescimento, como razão de área foliar (RAF), razão de peso foliar (RPF) e área foliar específica (AFE) apresentaram respostas diferenciais ao fotoperíodo em relação às outras características de crescimento analisadas anteriormente. Considerando-se a equação de regressão para RAF, constatou-se efeito significativo tanto para o coeficiente de regressão linear como para o coeficiente de regressão quadrática.

A equação de regressão para essa característica está apresentada na Figura 5, A, e mostra que há uma redução da RAF em função do fotoperíodo, embora, a partir de 16 horas de luz, observa-se uma leve tendência de aumento da RAF. Essa característica permite detectar o particionamento de assimilados para as folhas em relação à biomassa seca total produzida pela planta (SCOTT e BATCHELOR, 1979). RAF pode decrescer em função do aumento no auto-sombreamento, havendo uma diminuição da área foliar útil. Essa queda na RAF é ontogênica e significa que progressivamente a quantidade de assimilados destinados às folhas é diminuída (SCOTT e BATCHELOR, 1979). Da mesma maneira que para RAF, observou-se efeito significativo do fotoperíodo para RPF, como pode ser constatado pelos coeficientes de regressão linear e quadrática. De acordo com a analise de regressão, o comportamento da RPF foi similar ao do RAF, ou seja, houve inicialmente um decréscimo nessa característica quando o fotoperíodo aumentou de 8 para 16 horas. Em contrapartida, a alteração do fotoperíodo de 16 para 20 horas conduziu a uma tendência de aumento (Figura 5, B).

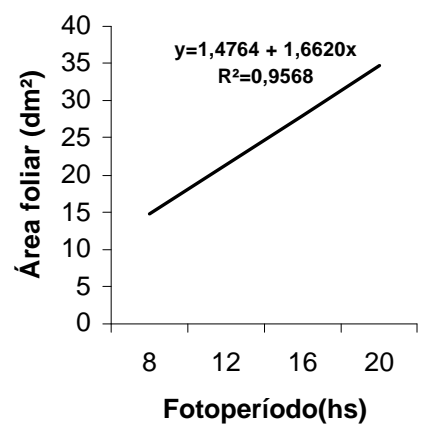

B

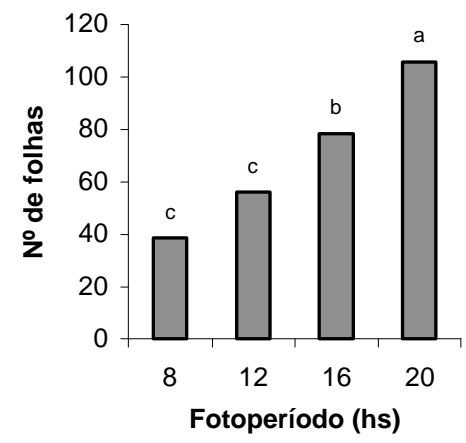

FIGURA 4 - Áreas foliares (A) e número de folhas (B) de plantas de guaco em função dos diferentes fotoperíodos, após 90 dias. As médias seguidas pelas mesmas letras não diferem entre si pelo teste de Scott Knott a 5\% de probabilidade.

Ciênc. agrotec., Lavras. V.27, n.6, p.1293-1300, nov./dez., 2003 
Para a regressão de AFE, da mesma forma que para RAF e RPF, foram observados efeitos significativos para coeficientes de regressão linear e quadrática.

Observa-se pela Figura 6 que houve redução da AFE com o aumento do fotoperíodo. Resultados semelhantes foram obtidos por vários autores, como Lorenzen e Ewing (1990) e por Castro (1999), em confrei. De acordo com Benincasa (1988), a área foliar específica (AFE) é a relação entre a área foliar e a biomassa seca das folhas e que fornece um indicativo da espessura da lâmina foliar. Analisando comparativamente os resultados de área foliar e biomassa foliar com os de RAF e RPF (Figuras 5, A e B) e AFE (Figura 6), observa-se uma lógica conceitual de respostas aos fotoperíodos testados.

A

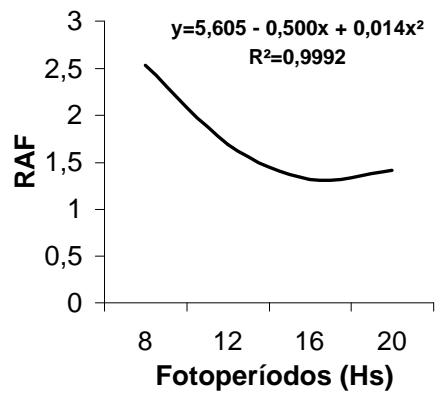

A redução da AFE nas plantas de guaco em fotoperíodos crescentes foi acompanhada de folhas mais espessas submetidas, sobretudo, a fotoperíodos de 16 e 20 horas, em relação àquelas submetidas a 8 e 12 horas (Tabela 1). Esses resultados foram decorrentes de um incremento acentuado na biomassa seca das folhas. Maiores valores de AFE de plantas de guaco encontrados sob fotoperíodos de 8 horas estão associados ao componente anatômico, ou seja, à redução significativa da espessura total do limbo (Tabela 1), o que foi acompanhado por alterações na espessura das camadas epidérmicas e das células do mesofilo (Tabela 1), podendo, ainda, estar relacionado com densidade celular, espessura de parede e outras características celulares e teciduais relacionadas com variações à exposição de luz.

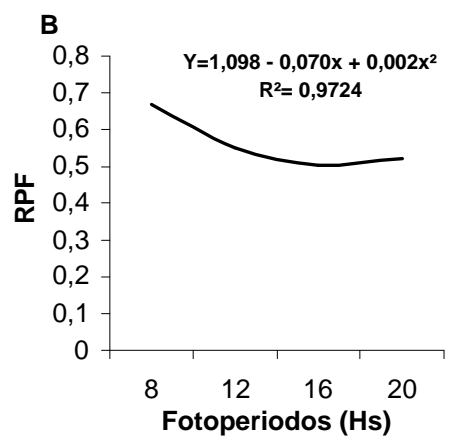

FIGURA 5 - Razão de área foliar (RAF), (A) e razão de peso foliar (RPF), (B) de plantas de guaco submetidas a diferentes fotoperíodos, após 90 dias.

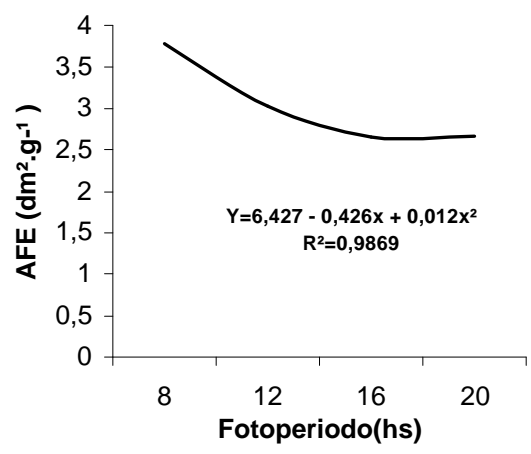

FIGURA 6 - Área foliar específica (AFE) de plantas de guaco submetidas a diferentes fotoperíodos, após 90 dias.

Ciênc. agrotec., Lavras. V.27, n.6, p.1293-1300, nov./dez., 2003 
TABELA 1 - Influência do fotoperíodo na espessura $(\mu \mathrm{m})$ das estruturas anatômicas de folhas de guaco (médias de sessenta repetições).

\begin{tabular}{cccccc}
\hline \multirow{2}{*}{ Fotoperíodos } & \multicolumn{2}{c}{ Epiderme } & \multicolumn{2}{c}{ Parênquima } & \multirow{2}{*}{$\begin{array}{c}\text { Espessura Total } \\
\text { do Limbo }\end{array}$} \\
\cline { 2 - 5 } & Abaxial & Adaxial & Paliçádico & Esponjoso & do \\
\hline 8 horas & $16,969 \mathrm{~d}$ & $18,587 \mathrm{~d}$ & $54,562 \mathrm{c}$ & $219,245 \mathrm{c}$ & $309,365 \mathrm{c}$ \\
12 horas & $18,708 \mathrm{c}$ & $36,039 \mathrm{c}$ & $70,409 \mathrm{~b}$ & $245,428 \mathrm{~b}$ & $370,585 \mathrm{~b}$ \\
16 horas & $22,278 \mathrm{~b}$ & $45,361 \mathrm{~b}$ & $74,752 \mathrm{a}$ & $266,012 \mathrm{a}$ & $408,404 \mathrm{a}$ \\
20 horas & $24,882 \mathrm{a}$ & $47,559 \mathrm{a}$ & $72,031 \mathrm{~b}$ & $261,238 \mathrm{a}$ & $405,711 \mathrm{a}$ \\
\hline
\end{tabular}

*As médias seguidas pela mesma letra, na coluna, não diferem significativamente entre si, pelo teste ScottKnott, ao nível de $5 \%$ de probabilidade.

\section{CONCLUSÕES}

O fotoperíodo influenciou positivamente as características associadas ao crescimento, anatomia foliar e fotossintética, como: produção de biomassa total, área foliar, número de folhas, particionamento de biomassa para os diversos órgãos da planta. Em relação à RAF, RPF e AFE, esses índices apresentam-se maiores sob fotoperíodos mais curtos. A menor área foliar específica (AFE) observada sob fotoperíodos mais longos foi acompanhada por um aumento da espessura foliar.

\section{REFERÊNCIAS BIBLIOGRÁFICAS}

ALVARENGA, A. A. Estudo de alguns aspectos do desenvolvimento do feijão jacatupé (Pachyrrhizus tuberosus Lam. Spreng). 1987. 74 f. Tese (Doutorado em Biologia Vegetal) - Universidade Estadual de Campinas, Campinas, 1987.

BENINCASA, M. M. P. Análise de crescimento de plantas. Jaboticabal: FCAV-UNESP, 1988. 41 p.

CASTRO, A. H. F. Aspectos fisiológicos, fotoquímicos de plantas de confrei (Symphytum officinale L.). 1999. 125 p. Dissertação (Mestrado em Fisiologia Vegetal) - Universidade Federal de Lavras, Lavras, 1999.

ENGELS, C.; SCHWENKEL, J.; ELBEDEWYIR, R.; SATTELMACHER, R. B. Effect of the developmental stage of potato seedlings on recovery after transplanting to the field end on tuber yield. Journal of Agricultural Science, Cambridge, v. 1224, n. 2, p. 213-218, Apr. 1995.
HAY, R. K. M. The influence of photoperiod on dry-matter production of grasses and cereals. The New Phytology, London, v. 116, p. 233-254, 1990.

JUNTILLA, O.; SVENNING, M. M.; SOLHEIM, B. Effects of temperature and photoperiod on frost resistence of white clover (Trifolium repens) ecotyph. Phisyologia Plantarum, Copenhagem, v. 79, n. 3, p. 435-438, July 1990.

KIGEL, J.; KOLLER, D. Analysis of the control of development in Oryzopsis miliacea by the light environment. Journal of Experimental Botany, [S.1.], v. 21, p. 3-16, 1970.

LETCHAND, W.; GOSSELIN, A. Transpiration essential oil gland, epicuticular wax and morphology of Thymus vulgaris are influenced by light intensity and water supply. Journal Horticultural Science, [S.1.], v. 71, n. 1, p. 123-134, 1996.

LORENZEN, J. H.; EWING, E. E. Changes in tuberization and assimilate partitioning in potato (Solanum tuberosum) during the first 18 days of photoperiod treatment. Annals of Botany, New York, v. 66 , n. 4 , p. $457-464$, Oct. 1990.

MOREIRA, M. F.; VIEIRA, C. C. J.; ZAIDAN, L. B. P. Efeito do fotoperíodo no crescimento e no padrão de acúmulo de frutano em plantas aclimatizadas de Gomphrena macrocephala St. Hil. (Amaranthaceae). Revista Brasileira de Botânica, São Paulo, v. 22, n. 3, p. 1-13, 1999. 
PEREIRA, A. M. S. Propagação e co-cultivo de células como fatores predisponentes à produção de cumarina em Mikania glomerata Sprengel (guaco). 1997. 82 f. Tese (Doutorado em Agricultura) - Universidade Estadual de São Paulo, Botucatu, 1997.

RANCANCIO, V. J. F.; PERES, L. E. P.; ZAIDAN, B. P.; PEREIRA, M. F. A. Influência do fotoperiodo em interação com a temperatura no desenvolvimento de plantas de Solidaster luteus. Revista Brasileira de Fisiologia Vegetal, [S.1.], v. 8, n. 2, p. 131-138, 1996.

SCOTT, H. D.; BATCHELOR, J. T. Dry weight and leaf area productions rates of irrigated determinate Soybeans. Agronomy Journal, Madson, v. 71, p. 782, 1979.

THOMAS, B.; VINCE-PRUE, D. Photoperiodism in plants. 2. ed. Califórnia: Academic, 1997. 428 p. 